\title{
LA PRODUCCIÓN DE CONOCIMIENTO ANTROPOLÓGICO SOCIAL EN CHILE POSTRANSICIÓN: DISCONTINUIDADES DEL PASADO Y DEBILIDADES PRESENTES
}

\author{
Stefano Palestini, Claudio Ramos y Andrea Canales ${ }^{1}$
}

\section{* Introducción}

Resumen

Se caracterizan las principales tendencias de la reciente investigación antropológica social chilena (años 2000-2006), situándolas en la trayectoria histórica de la disciplina en el país. A través del análisis de investigaciones publicadas, de sus marcos paradigmáticos, áreas temáticas, diseños teórico-metodológicos y de la audiencia a la que se dirigen, se concluye una alta dispersión temática, inconsistencia paradigmática y debilidades en la construcción teórico-metodológica. Se propone, además, la posibilidad de que esto se deba a una discontinuidad entre la fase fundacional de la disciplina y el momento actual, considerando los procesos políticos ocurridos en el país en las últimas décadas.

Palabras claves: antropología - Chile - producción de conocimiento cienciometría.

This paper considers the main trends in recent Chilean social anthropological production (2000-2006), with reference to the discipline's history in the country. Analysis of the contents published by Chilean anthropologists during that period allowed for the ability to distinguish and compare their paradigms and audiences, their areas of thematic interest, and their methodological and theoretical frameworks. Results show a large thematic dispersion, major paradigmatic inconsistencies and weaknesses in theoretical and methodological designs, without clear tendencies towards the creation of an applied anthropology or outlining a proximate configuration of otherness. The conclusion explores the possibility that such discontinuities might result from university disruptions during the dictatorship, which cut off the discipline at foundational moments.

Key words: anthropology - Chile - knowledge production science metrics.

Recibido:enero 2008. Aceptado: diciembre 2009.
Desde los años 60 la antropología social a nivel mundial ha experimentado una profunda renovación tanto de sus focos de interés y su aproximación epistemológica, como de sus teorías y metodología. Este proceso ha sido motivado por la transformación sociopolítica de las sociedades coloniales, así como por la crítica ética, política y epistemológica al exotismo que caracterizó el punto de vista antropológico desde sus inicios como disciplina científica.

Dicho proceso se vivió con intensidad en los principales centros de producción de conocimiento antropológico, como Inglaterra, Francia, Estados Unidos y Alemania, pero también en el resto de los países que contaban con programas de antropología. Muchos de ellos habían sido colonias, o bien, en el caso de los países latinoamericanos, Estados naciones con un alto grado de dependencia y poblaciones indígenas, que constituyeron polos de atracción para el trabajo de campo de antropólogos sociales provenientes de los países centrales durante la primera mitad del siglo XX.

Si bien la renovación de la antropología social en los distintos países ha tenido diversas direcciones dependiendo de las características institucionales de la disciplina y de sus particulares realidades sociales, políticas e intelectuales, es posible, no obstante, reconocer algunas tendencias generales. La crítica al exotismo, una tendencia compartida por buena parte de la antropología a nivel mundial, ha llevado al progresivo reemplazo de una epistemología basada en la alteridad radical, vale decir, en la comprensión del otro en cuanto esencialmente diferen-

\footnotetext{
1 Departamento de Sociología, Universidad Alberto Hurtado. Cienfuegos 46, Santiago, CHILE. Email: spalesti@uahurtado.cl, claudior@uahurtado.cl, andrea.canales@sociology.ox.ac.uk
} 
te, por líneas de investigación basadas en una alteridad próxima, y orientadas a la comprensión de fenómenos de la sociedad moderna; entendida ésta como una colectividad en la que están inmersos observadores y observados (Peirano 1998, 2003).

Esta tendencia ha disipado la frontera espacial y cognitiva entre el "hogar" del antropólogo, y el "afuera" en el que efectuaba el trabajo de campo, dando origen a una anthropology at home, que en algunos países ha adquirido marcados rasgos nacionales generando comunidades de investigadores con capacidad de sostener un diálogo crítico con teorías y enfoques provenientes de los centros de producción de conocimiento antropológico. Paralelamente, se ha venido produciendo un fortalecimiento de la antropología aplicada, cuyos principales destinatarios ya no son los pares académicos, sino las organizaciones de la sociedad civil, las comunidades, instituciones gubernamentales y empresas privadas constituidas como demandantes y clientes de conocimiento antropológico. Se trata de una antropología orientada a la resolución de problemas sociales desde una perspectiva pragmática y crítica (Peacok 1997; Kottak 2002).

En este artículo examinaremos desde la perspectiva de la sociología de la ciencia, las tendencias de la antropología social reciente en Chile. Este es un país étnicamente diverso que fue escenario de investigaciones antropológicas desde fines del siglo XIX, y que vivió sus procesos de institucionalización universitaria y nacionalización de la disciplina durante las décadas de 1960 y 1970 , en momentos en que, por un lado, se desarrollaban procesos de revisión epistemológica de la antropología mundial, y por otro, agudas transformaciones políticas en el país.

Luego de presentar la metodología utilizada, efectuamos una breve reseña de la trayectoria histórica de la disciplina, resaltando lo que hemos denominado como las discontinuidades entre el primer período de producción de conocimiento antropológico y el segundo período de institucionalización universitaria. Posteriormente, analizamos la producción antropológica chilena reciente, centrándonos en sus paradigmas de conocimiento y en la relación epistemológica entre el antropólogo y su objeto, para después analizar las áreas temáticas, la construcción teórica y metodológica de las investigaciones y el público al que éstas van dirigidas. Finalmente ofrecemos una visión sintética de las formas de investigación antropológica en Chile y las conclusiones.

\section{* Metodología}

Las disciplinas científicas son un objeto de estudio complejo. A partir de los desarrollos de la sociología de la ciencia es posible distinguir dos grandes dimensiones desde las cuales podemos abordarlo. Una primera dimensión corresponde al análisis de los textos científicos-artículos, libros, documentos de trabajo, manuales, etc.- entendiéndolos como el sustrato material a través del cual se dan a conocer las comunicaciones científicas. Una segunda dimensión corresponde al estudio del campo científico y las redes que lo componen: redes en las que se enrolan tanto organizaciones -de producción, de financiamiento, de publicación- como agentes -científicos, editores, patrocinadores, revisores, entre otros-(Ramos 2008).

En este artículo nos centraremos en la primera dimensión, es decir, nos aproximaremos a la antropología social chilena a través de sus textos, en particular aquellos correspondientes a investigaciones del período de postransición a la democracia en el que han desaparecido los obstáculos políticos para el desarrollo de las ciencias sociales, siendo el propio Estado uno de los principales demandantes de investigaciones científicas sociales. Las distintas disciplinas han experimentado un crecimiento en sus recursos institucionales y el campo ha adquirido o recuperado, una significativa legitimidad social (Garretón 2005). Por razones de factibilidad el estudio se centró en las investigaciones publicadas entre los años 2000 y $2006 .^{2}$

Los textos se consiguieron buscando en organizaciones, tanto en Santiago como en regiones, incluyendo universidades, centros de investigación, organismos internacionales y del Estado. El criterio de selección consistió en que al menos uno de los autores tuviera un grado académico en antropología (licenciatura, magís-

\footnotetext{
${ }^{2}$ Para análisis comparativos entre la antropología social, la ciencia
política y la sociología en el mismo intervalo de tiempo ver Ra-

2 Para análisis comparativos entre la antropología social, la ciencia
política y la sociología en el mismo intervalo de tiempo ver Ramos y colaboradores (2008).
} 
ter o doctorado) cuando se publicara la investigación. Con ello se procuró dar objetividad a dicha selección, de modo de no recurrir a una definición a priori sobre qué es una investigación antropológica y qué no lo es, definición que habría limitado la búsqueda. La decisión de considerar como investigación antropológica a aquella conducida por antropólogos, aumenta la variabilidad de textos y la posibilidad de incorporar al corpus distintos perfiles de investigación. La homogeneidad o heterogeneidad del campo queda de este modo sujeta al campo mismo, y a las trayectorias potencialmente divergentes de sus agentes, y no a una definición previa de quienes efectúan la búsqueda.

Otros criterios de selección consistieron en que los autores fueran chilenos o extranjeros radicados en el país durante el período considerado (2000-2006), y que las publicaciones dieran cuenta de investigaciones empíricas o teóricas. El carácter empírico se entendió en sentido amplio. Se consideraron investigaciones empíricas aquellas en que hubiera una conexión con la realidad social valiéndose de materiales provenientes de la experiencia social, vía entrevista, encuesta, observación directa, uso de datos secundarios, análisis de documentos o material audiovisual, u otros métodos. Para avalar el carácter empírico se consideró que el texto debía tener una descripción, aunque fuera somera, de los métodos empleados. En el caso de las investigaciones teóricas, se consideraron aquellos textos que efectuaran elaboraciones conceptuales sistemáticas y originales excluyendo ensayos (elaboraciones sin referencia explícita a literatura o conceptos disciplinares) o monografías sobre un único autor.

Los textos recolectados fueron sometidos a diversas revisiones por parte de los investigadores con el fin de asegurarse que cumplieran con los criterios de selección. Finalmente, se obtuvo un corpus de 112 textos, 97 investigaciones empíricas y 15 investigaciones teóricas. El proceso de búsqueda fue lo suficientemente exhaustivo como para que fuera plausible generalizar los resultados al universo de investigaciones de antropología social en Chile del período 2000-2006. Los textos fueron examinados con una pauta de análisis de contenido de 110 variables, y sometidos a análisis estadísticos y técnicas de análisis multivariables (análisis de conglomerados y de correspondencias múltiples).

\section{* Trayectoria de la disciplina}

Si bien la enseñanza universitaria y el ejercicio profesional de la antropología en Chile tienen poco más de 30 años -levemente anteriores a otras disciplinas de las ciencias sociales-, la investigación antropológica en el país data de finales del s. XIX. En efecto, es posible hablar de un período preuniversitario de la antropología chilena, que se inicia simbólicamente con la publicación de Los aborígenes de Chile de José Toribio Medina en 1883. y un segundo período, de institucionalización universitaria, que se inicia en 1954 con la creación del Centro de Estudios Antropológicos (CEA) de la Universidad de Chile (Arnold 1990; Bengoa 1998; Garretón 2005).

En el primer período la investigación antropológica se caracterizó por dos rasgos distintivos: fue realizada principalmente por extranjeros y se desarrolló bajo el alero institucional de los museos. En efecto, a fines del s. XIX la investigación antropológica fue llevada a cabo y financiada por sociedades científicas europeas tales como la Deutschen Wissenschaftlichen Vereines zu Santiago, fundada en 1885 y la Societé Scientifique du Chili fundada en 1891, cada una de las cuales mantendría publicaciones especializadas con regularidad hasta el advenimiento de la Primera Guerra Mundial (Arnold 1990; Orellana 1996).

Durante la primera mitad del s. XX, los investigadores continuaron siendo científicos europeos que arribaron al país emigrando de sus países de origen, o bien traídos por el gobierno chileno. Estos "sabios", como los denomina Bengoa (1998), asumieron funciones directivas en los distintos museos del país, y desde ellos emprendieron grandes proyectos de investigación que ligaron a la antropología social con la antropología física y la arqueología. Los grandes centros de investigación de la época fueron el Museo de Historia Natural, dirigido desde 1928 por el inglés Ricardo Latcham; el Museo de Historia Natural de Valparaíso y el de Concepción fundados en 1876 y 1902, respectivamente; el Museo de Etnología y Antropología de Chile, fundado en 1912 por Aureliano Oyarzún y en el que trabajarían Max Uhle y Martín Gusinde (Arnold 1990; Berdichewsky 2004). ${ }^{3}$

\footnotetext{
${ }^{3}$ La temprana institucionalización de la antropología en los museos no es exclusiva de Chile. En Francia, por ejemplo, los museos cum- 
Desde los museos se financiaban y diseñaban las investigaciones, y de ellos emanaban las publicaciones, así como los materiales arqueológicos encontrados. Además, fue en los museos donde tomaron lugar los debates teóricos -que en forma simultánea se estaban produciendo en los centros antropológicos europeos y norteamericanos- en los que se enfrentaron el evolucionismo sostenido por Latcham, con el difusionismo defendido por Oyarzún y Gusinde (Berdichewsky 2004). Debido al considerable número de investigaciones producidas desde los museos y a la conexión con los debates teóricos internacionales, algunos antropólogos nacionales han catalogado a las décadas entre 1920 y 1940, como el período más fructífero de la antropología nacional (Arnold 1990).

Como recuerda Berdichewsky, a mediados de la década de 1940 los "sabios" ya habían desaparecido de la escena antropológica nacional, no sólo por el fallecimiento de la mayoría de ellos, sino porque sus obras quedaron literalmente en los museos, donde habían sido producidas (Berdichewsky 2004). Surge entonces una generación de recambio, en la que figuran algunos pocos chilenos formados bajo la influencia de los "sabios", y numerosos extranjeros. ${ }^{4}$ Por la misma fecha comienza el desplazamiento institucional de la disciplina desde los museos a las universidades, primero tímidamente con la creación del CEA en 1954, por iniciativa del rector de la Universidad de Chile, Juan Gómez Millas y, de manera definitiva, con la creación del Departamento de Ciencias Antropológicas y Arqueológicas de dicha universidad en 1970 (Orellana 1988; Arnold 1990; Arroyo 2005).

plieron un papel predominante en la institucionalización de la antropología hasta la mitad del s. XX (Rogers 2001; Parkin 2005).

${ }^{4}$ La presencia de extranjeros siguió siendo decisiva en el ejercicio de la investigación antropológica hasta el golpe militar. La lista incluye a científicos extranjeros residentes como Alejandro Lipschutz y Grete Mostny, así como a otros que permanecieron temporalmente en el país realizando investigaciones y participando en la formación de los nuevos programas de antropología, tales como los norteamericanos Misha Titiev, Louis Faron, Junius Bird y Richard Schaedel, quien sería el primer director del CEA; el austriaco Oswald Menghin; los alemanes Emil Willems y Thomas Barthel; el noruego Thor Heyerdhal; el checo Milan Stuchlik y los franceses Annette Emperaire, Paul Rivet y Alfred Métraux. También hubo antropólogos latinoamericanos como Miguel León Portilla, Luis Guillermo Lumbreras, Luis Millones y Darcy Ribeiro, entre otros (Berdichewsky 2004).
La institucionalización universitaria continúa en regiones, creándose un programa de licenciatura en antropología en la Universidad de Concepción con el auspicio de la UNESCO en 1968. Ese mismo año, en Antofagasta se crea la carrera de antropología de la Universidad del Norte. En 1971 se funda la carrera de antropología en la Universidad Católica de Temuco con la participación del antropólogo checo Milan Stuchlik (Orellana 1996; Durán 2001).

Con el régimen militar, los jóvenes programas universitarios se vieron severamente afectados. Se cerró la mayoría de los programas de regiones y el Departamento de Antropología de la Universidad de Chile fue intervenido en 1982 y fusionado con el Departamento de Sociología. Curiosamente, la represión del Estado fue diferenciada en distintas ramas de la antropología. Mientras la antropología social fue prácticamente anulada y sus más connotados practicantes - tanto chilenos como extranjerosdebieron abandonar el país, los arqueólogos gozaron de cierta inmunidad, manteniendo sus cargos y continuando su labor investigativa. Para Berdichewsky - uno de los antropólogos que partió al exilio- el resurgimiento y revitalización de la antropología social en la década de los 80 se debe, en parte, a la labor de los arqueólogos que conservaron su espacio en las universidades (Arroyo 2005).

A pesar de la falta de recursos para la investigación y de las fuertes restricciones institucionales impuestas por el gobierno militar, la antropología social comienza a resurgir. En 1984 se crea el Colegio de Antropólogos, que nace con objetivos tanto gremiales como académicos, y que organiza los posteriores congresos de antropología realizados hasta la fecha. En 1988 se crea el primer programa de posgrado en antropología en la Universidad de Chile bajo la coordinación de María Ester Grebe, y en 1989 se crea la primera carrera de antropología impartida por una universidad privada, la Universidad Bolivariana (Arnold 1990). Hoy, la carrera se imparte en nueve universidades y hay tres programas de posgrado.

\section{La discontinuidad entre la antropología de los museos y la antropología universitaria}

En la trayectoria de la disciplina en Chile llaman la atención importantes discontinuidades entre el período preuniversitario, de institucionalización en los museos, 
y el período universitario. Una primera brecha de índole institucional es la diferencia significativa que existe entre una empresa científica concentrada en museos, y otra que lo haga en universidades. Enmarcada en museos, la generación de conocimientos obedece a un propósito acumulativo y de difusión restringida, mientras que en las universidades la investigación se vincula con la docencia y la aplicación del conocimiento. Sin embargo, la ruptura entre los dos períodos parece ir más allá de lo institucional llegando a afectar la manera en que los antropólogos, formados en los nuevos programas universitarios, valoran e interpretan el ejercicio de la disciplina por parte de sus antecesores.

El apelativo de "sabios", con el que Bengoa (1998) denominó a los antropólogos extranjeros tanto de la primera generación como a los de la generación de transición entre los dos períodos (p.e., Lipschutz, Stuchlik, Motsny), denota la ruptura a la que nos referimos. Según Bengoa, la antropología de los "sabios" estuvo fuertemente marcada por una imagen romántica de la disciplina, que era entendida por las élites nacionales como una afición culta de profesores extranjeros.

Entre ambos períodos hay también una discontinuidad epistemológica e ideológica. Los antropólogos de la época universitaria no comparten la aproximación efectuada por la antropología de los "sabios". Para Berdichewsky, se trataba de una antropología efectuada por europeos principalmente y centrada en "estudios puramente etnológicos, folclóricos o arqueológicos sobre las sociedades nativas del país (como los fueguinos, los mapuche, los aymara y los pascuenses)..." (2004: 86). Los investigadores adherían a teorías que luego serían vistas como conservadoras, tales como el evolucionismo de Tylor y Morgan o el difusionismo de los círculos culturales austro-alemanes, importado a Chile por $\mathrm{Gu}$ sinde (Barth et al. 2005). Según Bengoa, los "sabios" eran mucho más cercanos a las ciencias biológicas que a las sociales -y por ello, sus aproximaciones fuertemente positivistas-, manteniéndose ajenos a los debates sociales de la época. La principal crítica que hace este autor a la antropología practicada desde los museos, fue el negar que las problemáticas indígenas eran parte de la cuestión social (Bengoa 1998).
Las críticas anteriores apuntan a que la antropología efectuada hasta la institucionalización universitaria se caracterizó epistemológicamente por una alteridad radical (Peirano 1998); es decir, fue una antropología que supuso al "otro" como radicalmente diferente, donde la distancia que separa a la comunidad del investigador con la comunidad investigada es enorme en términos espaciales -europeos que viajan a estudiar comunidades nativas de un país latinoamericano-, y prácticamente infranqueable en términos cognitivos y culturales. ${ }^{5}$

Aunque algunos antropólogos chilenos reconozcan lo fructífero del período previo a la institucionalización universitaria (Arnold 1990), lo cierto es que la antropología nacional actual exhibe una brecha importante con la anterior. Es posible que entre ambos períodos faltara, además, un puente generacional. Por una parte, la antropología de los museos no generó escuela: fueron pocos los antropólogos chilenos discípulos de los "sabios"; hubo una segunda generación de chilenos que llegó a la antropología proveniente de otras disciplinas y que se formó con maestros como Lipschutz, en Santiago, o Stuchlik, en Temuco. Esta segunda generación que fue la que creó, de la mano de sus maestros europeos, los primeros programas universitarios, pudo haber actuado como puente entre ambos períodos, pero muchos de ellos debieron abandonar Chile una vez iniciado el régimen militar, con lo que su aporte académico en el país se vio truncado.

\section{* Desde dónde investigan los ANTropólogos CHILENOS}

Iniciaremos el análisis caracterizando los supuestos más básicos desde donde los antropólogos plantean sus interrogantes y diseñan sus estudios. En primera instancia, y siguiendo la aproximación de Kuhn (1971), hemos examinado los supuestos paradigmáticos de las investigaciones. Posteriormente, basándonos en una

\footnotetext{
${ }^{5}$ Los estudios de la década de 1930 efectuados por el estadounidense McBride sobre el campesinado chileno, así como los estudios indigenistas de Lipschutz de las décadas de 1940 y 1950 , son destacados por Bengoa (1998) y Berdichewsky (2004) como ejemplos de una antropología en contacto con su objeto de estudio y comprometida con la cuestión indígena.
} 
tipología propuesta por Peirano (1998), caracterizamos las investigaciones a partir del tipo de relación que establecen con su objeto de estudio.

\section{Paradigmas de conocimiento antropológico: La primacía de la interpretación}

Todo investigador, en su calidad de observador, posee ciertos esquemas de percepción y marcos de referencia que condicionan su práctica científica. Ahora bien, dichos esquemas cognitivos no son individuales, sino compartidos por quienes ejercen esa práctica, vale decir, por la comunidad científica. Algunos de estos supuestos son bastante transversales, mientras que otros difieren considerablemente entre las disciplinas e, incluso, entre escuelas y facciones al interior de una misma disciplina. A partir del análisis de las prácticas científicas, en particular de sus textos, es posible reconstruir los supuestos básicos que caracterizan a una disciplina o campo específico de conocimiento en un momento histórico.

Hay diferentes maneras de caracterizar y nominar estos supuestos paradigmáticos de la ciencia (Kuhn 1971). Aquí optamos por una terminología general y aplicable no sólo a la antropología, sino a las demás ciencias sociales. ${ }^{6}$ A pesar de que hay quienes sostienen la imposibilidad de aplicar el concepto kuhniano de paradigmas a las ciencias sociales, existe un relativo consenso acerca de la posibilidad de distinguir grupos paradigmáticos, no a partir de diferencias teóricas o metodológicas (lo que daría presumiblemente una miríada de "paradigmas" en ciencias sociales), sino a partir de los supuestos ontológicos, epistemológicos y axiológicos de las investigaciones. ${ }^{8}$ Los supuestos ontológicos son aquellos que refieren a la naturaleza de la realidad que se va a investigar; todo ser humano tiene supuestos ontológicos que actúan como condición de posibilidad de su actuar, sin embargo los científicos pueden llegar a concebir la realidad de manera bastante alejada a la

\footnotetext{
${ }^{6}$ Para un análisis comparativo de los supuestos paradigmáticos de la antropología, ciencia política y sociología chilenas, ver Ramos y colaboradores (2008).

7 Ver Orellana (1996) para el caso de la antropología y arqueología en Chile.

${ }^{8}$ Para una discusión más detallada de esta reapropiación del concepto de paradigma ver Guba y Lincoln (1998), Ramos (2005) y Ramos y colaboradores (2008).
}

apreciación de quienes la viven. Los supuestos epistemológicos refieren, por una parte, del modo en que el científico postula su relación con la realidad investigada y, por otra, al concepto de verdad y de "conocimiento científico" al que el investigador o la comunidad de investigadores adscriben. Finalmente, los supuestos axiológicos refieren al papel asignado a los valores y orientaciones normativas en la práctica científica.

A partir del análisis de contenido de las investigaciones antropológicas chilenas, se registraron distintos indicadores de los supuestos paradigmáticos, los que fueron incorporados a un análisis de conglomerados. Para generar los conglomerados se emplearon las siguientes variables: relación investigador-realidad, concepto de verdad, presencia de valores, concepto de realidad, índice de desarrollo metodológico positivista, índice de desarrollo metodológico interpretativo. Los cuatro primeros indicadores operacionalizan los supuestos paradigmáticos definidos previamente; los dos últimos índices miden las diferencias metodológicas de las investigaciones.

Mediante el análisis de conglomerados generamos tres grupos paradigmáticos significativamente diferenciados, a los que denominamos por sus características; interpretativo, interpretativo crítico y postpositivista. Los dos primeros grupos, si bien difieren en algunos indicadores, comparten elementos característicos del paradigma interpretativo. Éste se caracteriza por concebir la realidad social como una construcción de sentido (cultural o simbólica) que el investigador puede estudiar a través de un proceso de interpretación. La verdad científica para este paradigma es entendida como una construcción social consensuada argumentativamente (Guba y Lincoln 1998).

En las investigaciones correspondientes al primer grupo se observan distintas manifestaciones de oposición al concepto positivista de verdad como representación objetiva: se rechaza la contrastación empírica como método universal de verificación de las explicaciones y se sostiene, por ejemplo, que "nuestro propio contexto social e histórico orienta en gran medida la investigación y la interpretación en ciencias sociales" (Thomas y Salazar 2000: 88), y que "el interés [del registro etnográfico] no está en una intención probatoria de los hechos; ellos son y existen como tales, en la medida que existe un hombre y mujer que los pueda narrar" (Rodríguez et al. 2002:4). 
La realidad social se entiende como narraciones, discursos o experiencias que el investigador interpreta en un intercambio dialógico:

"...la relación etnográfica deja de ser puramente instrumental, sino también de mutua recomposición de sentido en el develamiento de lo cultural vía el encuentro de dos personas que se preguntan y responden desde los contenidos de sus respectivos colectivos" (Recasens 2003:15).

El segundo grupo denominado "interpretativo crítico" debido a que los rasgos interpretativos, si bien continúan siendo predominantes, se combinan con matices del paradigma crítico que le confiere a los valores yorientaciones normativas un papel mucho más determinante que el que poseen en las investigaciones propiamente interpretativas. Así por ejemplo, Sadler (2004: 20) conecta la interpretación de los sentidos y representaciones de las madres que dan a luz en los servicios públicos de salud, con el interés, típicamente crítico, de develar los mecanismos ocultos que hacen ver como naturales relaciones de dominación y discriminación. Son investigaciones en las que se aprecia un compromiso ético con la realidad estudiada:

"Además de su propósito central, este libro pretende lograr dos resultados adicionales, uno académico y otro práctico. El primero es ofrecer un modelo para el estudio de relaciones de clientelismo politico en otros sectores subalternos de la sociedad. El segundo es aportar ideas y orientaciones útiles a los sectores más democráticos de los partidos políticos progresistas, en sus esfuerzos por empoderar a las bases y forjar alianzas participativas para reducir el dominio de las máquinas clientelares y el control cupular al interior de esos partidos" (Durston et al. 2005: 17).

El tercer grupo generado por el análisis de conglomerado, reúne investigaciones con características postpositivistas. El postpositivismo es una versión reformada de la concepción positivista de la ciencia que supone a la realidad social como compuesta de estructuras o regularidades objetivas, independientes y externas a los sujetos y al propio investigador. El postpositivismo adhiere en lo fundamental a esta concepción ontológica realista, pero admite que toda observación científica está cargada teóricamente (rechazando el principio positivista de la tabula rasa) y considera a toda proposición científica como falseable y, por ende, hipotética (Guba y Lincoln 1998).
En las investigaciones asignadas a este tercer grupo desaparece la preocupación por los procesos interpretativos de narraciones, relatos, experiencias y discursos, dando lugar al establecimiento de regularidades, por lo general expresadas en términos de variables. Así, por ejemplo, en un estudio sobre el juicio moral en jóvenes y adolescentes se concluye que:

“...hay una correlación positiva con la permisividad moral, a mayor permisividad mayor cantidad de problemas percibidos en la propia vida. Se aprecia una asociación entre mayor permisividad, la percepción de poca felicidad y de mayor cantidad de problemas en la propia vida..." (Mathiesen et al. 2004: 18).

A diferencia de las investigaciones interpretativas, en las postpositivistas se adhiere explícitamente al postulado de la neutralidad valorativa:

"No podemos cerrar este artículo sin dejar de mencionar que nuestra mirada se reduce a una evaluación técnica del funcionamiento del programa, y no tiene relación con la legítima demanda por la recuperación de tierras indígenas que se hace al Estado chileno, cuya responsabilidad principal descansa en el movimiento mapuche, en conjunto con el compromiso de toda la ciudadanía" (Pizarro y Varas 2004: 151).

El $86.5 \%$ de las investigaciones de los dos primeros grupos, indica un claro predominio del paradigma interpretativo en la antropología social chilena, que la distingue de la sociología y la ciencia política en las que prima el postpositivismo (Ramos et al. 2008). Este resultado no es sorprendente pues históricamente los antropólogos, al tratar con grupos y comunidades culturalmente diferentes a su propia comunidad de origen, han dependido de la interpretación como herramienta central de sus métodos. Incluso en los inicios de la antropología científica, cuando el positivismo era el paradigma oficial de todas las ciencias sociales, los antropólogos debían emplear técnicas de interpretación para poder satisfacer la pretensión positivista de un conocimiento realista y holista de la comunidad estudiada (Marcus y Fischer 2000).

Si bien la interpretación es una constante en la investigación antropológica, el paradigma interpretativo surge como paradigma propiamente tal, cuando la representación objetiva de otra cultura se pone en entredicho, y la interpretación del "otro" se convierte en la principal 
preocupación epistemológica y ética de los antropólogos. A partir del surgimiento de dicho paradigma y el cuestionamiento a la representación naturalista del otro, la antropología social inicia un proceso de revisión epistemológica modificando fuertemente la manera en que históricamente se había relacionado con su objeto de estudio.

\section{La relación del antropólogo y su objeto: Alteridades diversas}

El surgimiento del problema de la interpretación del "otro", que está en la base del paradigma interpretativo en antropología social, conduce al desplazamiento del objeto de la antropología desde las culturas más exóticas y lejanas a la propia cultura del investigador, y a la propia práctica antropológica y etnográfica. Ambos procesos son causa y efecto de las críticas internas que se hacen los mismos antropólogos en la década de 1960, ante la toma de conciencia de que el colonialismo y los procesos de mundialización hacían inviable y ficticia la comprensión objetiva de un "otro distante" (Marcus y Fischer 2000).

En lo que sigue, nos interesa precisamente caracterizar el tipo de relación que mantienen los antropólogos chilenos con sus objetos de estudio, es decir, profundizar en los supuestos epistemológicos de la antropología nacional. Para ello seguiremos la tipología propuesta por Peirano $(1998,2003$ ) acerca de los tipos de alteridad (otherness) en la antropología social brasilera. La autora propone entender la relación de los antropólogos con sus objetos de estudio, como puntos en un continuo que va desde la mayor lejanía espacial y cognitiva del "otro" o mayor exotismo, hasta la mayor cercanía con el objeto de estudio, en la que el "otro" termina disolviéndose con "nosotros". En ese continuo, Peirano (1998) reconoce cuatro configuraciones, la alteridad radical, la alteridad en contacto, la alteridad próxima y el "nosotros" radical.

Este continuo tiene un carácter histórico ya que efectivamente, la antropología científica desde sus inicios en el s. XIX se ha ido desplazando desde una alteridad radical hacia una alteridad próxima. La primera, en el caso latinoamericano, y particularmente chileno, corresponde a las investigaciones efectuadas desde los museos por investigadores extranjeros (los "sabios") acerca de los aborígenes americanos. Peirano (1998), reconoce en los estudios sobre comunidades migrantes una versión actual de estudios basados en una alteridad radical.

La alteridad en contacto surge cuando la antropología europea toma conciencia del vínculo político histórico que los liga a los "otros" estudiados, a saber, el colonialismo. En el caso de Brasil, este tipo de alteridad está representada por la teoría de las "fricciones interétnicas" de Cardoso de Oliveira, que fue una reacción a las teorías norteamericanas del cambio cultural y la aculturación (Peirano 1991, 1998). En el caso chileno se podría encontrar en la obra indigenista de Lipschutz un equivalente a este tipo de estudios (Berdichewsky 2004).

La alteridad próxima corresponde a los estudios antropológicos sobre fenómenos de la propia cultura occidental o de origen de los investigadores. De acuerdo a Marcus y Fischer (2000), se puede decir que la antropología se vuelca hacia este tipo de alteridad cuando toma conciencia de que los territorios prístinos y las culturas completamente extrañas ya no existen, si es que alguna vez - en la historia de la disciplina- verdaderamente existieron. En la antropología brasilera, el interés por la alteridad próxima va de la mano con la recepción de teorías microsociológicas como el interaccionismo simbólico y sus temas urbanos: sectores populares, relaciones de género y generacionales, prostitución, familia, entre otros (Peirano 1998). La recepción de estas teorías en los años 70 convierte a la antropología brasilera en la contraparte de la sociología, por ese entonces de inspiración funcionalista y marxista. En Chile, hay antecedentes de que cursos sobre autores interaccionistas como Goffman, así como talleres de antropología urbana, fueron introducidos tempranamente en el currículo de la licenciatura de la Universidad de Chile, lo que evidencia que la antropología chilena se caracterizó desde los inicios de su institucionalización universitaria por la presencia de una alteridad próxima en directa contraposición a la antropología practicada desde los museos (Arnold 1990).

La última configuración de Peirano, el "nosotros" radical, puede verse como una profundización del proceso anterior, cuando la antropología y las ciencias sociales en general, inician un proceso de auto-observación de sus propios "modos de observar" (Peirano 1998). 
A partir del análisis de contenido hemos caracterizado las investigaciones antropológicas chilenas según los tipos propuestos por Peirano. Si bien se observa un predominio de la alteridad próxima, hay, no obstante, una presencia importante de investigaciones que corresponden a alteridad en contacto y a alteridad radical. Existe un $17 \%$ de investigaciones en el que la alteridad radical está representada por el estudio de las creencias, ritos y costumbres de los pueblos originarios (p.e., Van Kessel 2000; Moulian 2002). Dentro de este tipo de investigaciones, el estudio de Gavilán propone "...describir e interpretar la forma en que la población aymara del altiplano del norte de Chile piensa y practica la división del trabajo por género" (2002: 102).

La alteridad en contacto, aquella que se basa en la interrelación del "otro" -representado por pueblos indígenas y comunidades- y el "nosotros" - entendido fundamentalmente en términos nacionales- corresponde al $28.6 \%$ de las investigaciones. Se manifiesta en estudios que abordan el conflicto étnico (p.e., Merino et al. 2001) y en aquellos inspirados en el multiculturalismo y en el interculturalismo (p.e., Poblete 2002; Gundermann et al. 2003). Al igual que en las investigaciones caracterizadas como alteridad radical, el objeto de estudio lo constituyen comunidades étnicas o pueblos originarios, sin embargo, la relación con dicho objeto es distinta. Las comunidades étnicas no son vistas como un otro distante, sino que se reconocen como un otro en el diálogo, y a veces en el conflicto, interétnico. Así, por ejemplo, se estudia cómo son representados los mapuche en documentales y películas chilenas (Carreño 2005) o se analizan los sitios en internet a través de los que las organizaciones mapuche se expresan cultural y políticamente (Godoy 2003). En otras investigaciones, el énfasis está puesto en los efectos de las instituciones nacionales sobre los pueblos originarios, analizándose la acción institucional sobre la conformación de la identidad étnica de los pueblos indígenas (Gundermann et al. 2005), la relación entre la descentralización del Estado y la etnicidad de las poblaciones aymara y atacameñas (Gundermann 2003), y los efectos de las políticas indígenas sobre las condiciones de vida y la identidad étnica de los pueblos originarios (Aravena 2005; Castro 2005).
La alteridad próxima alcanza un $48.2 \%$ de las investigaciones y está representada en Chile por estudios acerca de grupos o subculturas urbanas, tales como los grupos de hip hop (Arriagada 2006), la cultura electrónica y las prácticas de consumo de éxtasis (Matus 2005); sobre desarrollo local y políticas públicas (Márquez 2002; Cancino 2006); y sobre sexualidad y relaciones de género (p.e., Herrera 2004; Benavente y Vergara 2006).

La antropología chilena exhibe un muy incipiente interés en el "nosotros radical", es decir, la autorreflexión sobre la práctica antropológica; esto se manifiesta en la casi inexistente literatura acerca de la antropología, en comparación, por ejemplo, con investigaciones sobre la sociología chilena. Lo mismo se puede decir para las investigaciones sobre científicos sociales y teóricos con influencia en la antropología chilena en su período preuniversitario, con la sola excepción de Berdichewsky (2004). El 4.5\% de investigaciones correspondientes al "nosotros radical", está representado principalmente por trabajos teóricos desarrollados en la Universidad Católica de Temuco acerca de la antropología de la Araucanía inspirada en Stuchlik (Durán et al. 2005). La investigación "Fotografías de cuerpos indígenas y la mirada erótica: Reflexiones preliminares sobre algunos casos del confín austral" (Carreño 2002), es una interesante muestra de autorreflexividad antropológica, en la cual se interpretan fotografías tomadas por etnólogos franceses a comienzos del s. XX en la Araucanía y en la Patagonia, y se comparan con fotografías eróticas que se difundían en Francia en la misma época, evidenciando coincidencias entre ambos registros. El autor concluye que: "las fotografías de cuerpos indígenas se producían intensamente, transitando en un terreno ambiguo, donde la gran excusa era la antropología y los usos científicos que ésta le daba a las imágenes" (Carreño 2002:7).

La antropología social chilena muestra una diversidad considerable de posicionamiento frente a su objeto. No es posible hablar de un tránsito definido hacia una alteridad próxima, tránsito que observa Peirano en Brasil. Si bien la alteridad próxima predomina, existe un importante número de antropólogos que continúa investigando comunidades étnicas, ya sea en cuanto "otros" diferentes, u "otros" en contacto con los procesos y fenómenos propios de la sociedad moderna occidental. 


\section{* Qué se investiga, cómo se investiga Y PARA QUIÉN SE INVESTIGA}

Tradicionalmente el núcleo temático de la antropología sociocultural ha sido el estudio de los patrones culturales de las poblaciones humanas (Kottak 2002). Sin embargo, a lo largo de su historia, la disciplina se ha abierto a nuevas áreas temáticas, algunas de las cuales son comunes con otras disciplinas de las ciencias sociales. A través del análisis de contenido, hemos determinado 11 áreas temáticas en las investigaciones antropológicas nacionales. Se ha procurado homologar las categorías con las propuestas por Arnold (1990), de manera de poder establecer tendencias. ${ }^{9}$

Como se aprecia en la Tabla 1, las áreas temáticas más representadas son: desarrollo local, ecología y medio ambiente; $;^{10}$ cuerpo, salud, medicina;; Estado nación, pueblos originarios, migraciones ${ }^{12}$ y comunidades, creencias, ritos. ${ }^{13}$ Las dos primeras, que tenían una mayor representación en el primer período, constituyen dos áreas importantes de la antropología social vinculadas a la antropología aplicada (Okongwu y Mencher 2000; Kottak 2002; Arnold 2005). La tercera área temática agrupa investigaciones que tratan fundamentalmente acerca de la relación entre Estado y minorías étnicas, ya sea pueblos originarios o migrantes. La cuarta área predominante corresponde al núcleo temático tradicional de la antropología, el estudio de las costumbres, ritos y

\footnotetext{
${ }^{9}$ El estudio de Arnold consistió en un análisis de contenido de 84 investigaciones que corresponden al universo de las tesis de pregrado efectuadas desde el primer egresado de la Licenciatura en Antropología Social de la Universidad de Chile en 1977, hasta el año 1987. Se trata de investigaciones empíricas y teóricas, por lo que podemos concluir que es una muestra similar a la nuestra. Según Arnold, la institucionalización de la antropología en Chile está estrechamente vinculada con el desarrollo de la disciplina en la Universidad de Chile: "en la práctica son los egresados de la Universidad de Chile la principal, si no única, fuente de antropólogos sociales de nuestro país" (1990: 15), por lo que los resultados de su estudio serían plausiblemente generalizables a la realidad de la antropología nacional, para el período considerado.

${ }^{10}$ En el estudio de Arnold esta categoría se denomina: antropología económica, desarrollo, ecología cultural.

${ }^{11}$ Antropología médica, en Arnold (1990).

${ }^{12}$ Aculturación, migraciones y minorías étnicas, en Arnold (1990).

${ }^{13}$ Antropología de las creencias, religión y valores culturales, en Arnold (1990).
}

creencias de comunidades y pueblos no occidentales. Estas dos últimas áreas tienen una baja representación en el primer período, que contrasta con la importancia que adquieren en el segundo.

Arnold (1990) interpretaba el contraste entre la baja representación de las temáticas más tradicionales y la alta representación de la antropología del desarrollo y de la salud como un indicador de que la antropología nacional tendía a orientarse hacia una antropología aplicada. Este tránsito hacia una antropología aplicada también se observa a nivel internacional, puesto que cada vez se involucra más con aspectos tales como las políticas de desarrollo y bienestar social, las migraciones y los conflictos medioambientales (Okongwu y Mencher 2000). Nuestro estudio muestra que, si bien las temáticas de la antropología aplicada están representadas, no existe una tendencia desde las temáticas tradicionales a las aplicadas. Más de un tercio de las investigaciones se enfoca al estudio de comunidades y sus sistemas de creencias, o en la relación entre Estado nación y pueblos originarios. A diferencia de la muestra de textos de Arnold, nuestro estudio incorpora investigaciones llevadas a cabo en diversos centros, muchos de ellos situados en el sur y en el norte del país. Puede ser que para los antropólogos de estos centros el estudio de las relaciones entre Estado y minorías étnicas, así como el estudio de los patrones culturales de comunidades, sí sean áreas prioritarias, tanto o más que las áreas de la antropología aplicada. Los datos parecen indicar que el realce de los estudios sobre temas relacionados con comunidades y pueblos originarios es nacional y obedece a que el reconocimiento de los pueblos originarios (o la "emergencia indígena" como la ha denominado Bengoa), ha tenido un mayor peso en la agenda pública desde 1990, lo que puede haber repercutido en las orientaciones temáticas de la antropología nacional (Bengoa 2000).

Algunas áreas han emergido tímidamente. Estratificación y desigualdad es un área no reportada en las investigaciones del primer período, y que para el segundo reúne 7.1\% de las investigaciones. Algo similar sucede con los estudios urbanos. Se trata de áreas propias de la sociología, pero en las que la antropología internacional ha incursionado hace ya varias décadas. En el caso de la antropología chilena, la aparición de estas áreas puede ir de la mano con la interdisciplinariedad evidenciada actualmente en- 
tre la antropología social y la sociología, inexistente entre los años 1977-1987 (Ramos et al. 2008). El área temática "consumo cultural", que no existía en el período inicial, tiene una bajísima representación hoy. Corresponde aproximadamente a los llamados estudios culturales, que tanto en Estados Unidos como en Europa son frecuentados por antropólogos y otros científicos sociales.

En síntesis, la antropología chilena actual se caracteriza por una amplia diversidad y fragmentación de sus intereses temáticos. Las nuevas áreas coexisten con los temas tradicionales, por lo que no es posible sostener que en nuestro país la antropología transite hacia una antropología aplicada.

\section{Construcción teórica de las investigaciones}

Las teorías, conjunto de relaciones entre conceptos y proposiciones entretejidas argumentativamente, son parte fundamental de la construcción de las investigaciones en ciencias sociales. A través de ellas, los investigadores constituyen el objeto o ámbito de estudio, y conectan su investigación con el núcleo conceptual propio de su disciplina. Mediante el análisis de contenido hemos registrado los tipos de teorías que utilizan las investigaciones antropológicas chilenas, así como el uso que de ellas hacen. Nos interesa saber también el nivel de conexión de las investigaciones con el núcleo conceptual de la disciplina a nivel internacional.

En cuanto al tipo de teorías, es posible distinguir entre las "grandes teorías" y las "teorías de rango medio". Las primeras consisten en sistemas teóricos generales que permiten una comprensión global y abarcadora de la realidad social y sus fenómenos. Las teorías de rango medio, por su parte, son cuerpos teóricos acotados a ámbitos específicos, cuya validez y generalización se restringe exclusivamente a dichos ámbitos de la realidad social (Merton 1957).

La Tabla 2 muestra el cruce del tipo de teoría utilizada y su nivel de uso, haciendo evidente la baja utilización de teorías en las investigaciones antropológicas chilenas. El uso sustantivo de teorías, vale decir, cuando se hace un tratamiento cuidadoso de los conceptos y se los emplea en la construcción y diseño de la investigación, solo alcanza un $24 \%$ de las investigaciones. El resto hace un uso precario de teorías o simplemente no utiliza ninguna.

\begin{tabular}{|l|c|c|}
\hline \multicolumn{1}{|c|}{ Área temática } & $\mathbf{1 9 7 7 - 1 9 8 7}$ & $\mathbf{2 0 0 0 - 2 0 0 6}$ \\
\hline Comunidades, creencias, ritos & 8.3 & 17.9 \\
\hline Estado nación, pueblos originarios, migraciones & 9.5 & 17.9 \\
\hline Estudios urbanos, subculturas urbanas & 9.5 & 5.4 \\
\hline Desarrollo local, ecología y medio ambiente & 16.6 & 12.5 \\
\hline Estudios organizacionales, políticas públicas & 0 & 10.7 \\
\hline Estratificación, desigualdad & 0 & 7.1 \\
\hline Género, familia, mujer & 9.5 & 7.1 \\
\hline Consumo cultural, estudios culturales & 0 & 1.8 \\
\hline Cuerpo, salud, medicina & 19 & 9.8 \\
\hline Educación & 8.3 & 1.8 \\
\hline Teoría, epistemología & $\mathbf{1 0 0}(\mathbf{n}=\mathbf{8 4})$ & $\mathbf{1 0 0}(\mathbf{n}=\mathbf{1 1 2})$ \\
\hline Otros & & 3.6 \\
\hline Total (\% y número de casos) & 14.5 & 6.3 \\
\hline
\end{tabular}

Tabla 1. Representación porcentual de áreas temáticas. Fuente: Período 1977-1988, reelaboración de datos obtenidos por Arnold y Haefner (1988) y Arnold (1990); Período 2000-2006, datos primarios de esta investigación. 


\begin{tabular}{|l|c|c|c|}
\hline \multirow{2}{*}{ Tipo de teoría que predomina } & \multicolumn{3}{|c|}{ Nivel de uso de teorías } \\
\cline { 2 - 4 } & Uso claro y sustantivo & Uso precario poco consistente & No uso \\
\hline Gran teoría & 11 & 10.4 & 0 \\
\hline Teoría de rango medio & 14.0 & 25.3 & 0 \\
\hline Ausencia de teoría & 0 & 0 & 39.3 \\
\hline
\end{tabular}

Tabla 2. Representación porcentual de tipos de teoría según nivel de usos de las teorías. El cálculo se hizo considerando el total de investigaciones empíricas y teóricas ( $\mathrm{n}=112$; ver Tabla 1$)$.

Si profundizamos en las formas de uso de la teoría en la investigación antropológica, se observa que en la mitad de las investigaciones la teoría asume la forma de proposiciones vagas y generales, con una relativa desconexión respecto al resto de la investigación. La teoría es utilizada primeramente como un "gran relato", es decir como marcos generales sin mayor conexión con el material empírico (Abend 2006), y secundariamente como marco conceptual orientador del análisis. La operacionalización de conceptos teóricos para su utilización en el análisis empírico y la elaboración de teorías a partir de la empiria -en el estilo de la Grounded Theory - son modos de uso muy minoritarios en la investigación antropológica (Tabla 3).

A través del análisis de contenido de las referencias bibliográficas de las investigaciones, se ha podido establecer qué autores teóricos son los más frecuentemente citados. ${ }^{14}$ Es importante destacar que la cita de autores no implica el uso sustantivo de sus teorías. En efecto, el bajo porcentaje de investigaciones que hacen uso importante de teorías, indica que las citas a autores teóricos corresponden a un uso más bien instrumental, para refrendar un argumento o para vincular ideas propias a una tradición teórica.

Arnold (1990) realizó un análisis similar con las referencias bibliográficas de las tesis de pregrado de los antropólogos de la Universidad de Chile para el período comprendido entre 1977-1987. En la Tabla 4 se comparan los autores más citados para ambos períodos. Las frecuencias son absolutas, y sólo sirven de referencia para ordenar jerárquicamente a los autores.

\footnotetext{
${ }^{14}$ Se hizo un análisis de contenido de las referencias de los textos de la muestra, que dio un total de 3304 referencias bibliográficas, lo que da un promedio de 29.5 referencias por texto.
}

Al comparar ambos períodos se encuentran importantes diferencias. Se podría decir que la antropología chilena se ha sociologizado en sus preferencias teóricas. En efecto, mientras en el período inicial los seis autores más citados eran claramente vinculables al núcleo teórico de la antropología, en el período reciente sólo dos autores (Geertz y Leach) son propiamente teóricos de la antropología. Ninguno de los autores más citados en el primer período, con la sola excepción del estructuralista Leach, se repite en el período reciente. En el primer puesto, Lévi-Strauss ha sido reemplazado por Bourdieu, un teórico social más bien transversal a las disciplinas, pero quizá más cercano a la sociología. ${ }^{15}$ El resto, Luhmann, Habermas y Foucault están fuertemente asociados a la teoría sociológica.

En 1990, Arnold se asombraba por las pocas referencias a teóricos y científicos sociales latinoamericanos. El único que figuraba en ese entonces era Germani con seis citas. La situación no ha variado en el período reciente, los únicos científicos sociales latinoamericanos que destacan son Stavenhagen (16 citas) y García Canclini (14 citas).

Como se ha señalado, las citas no reflejan necesariamente un uso sustantivo del autor, sino más bien el respaldo a afirmaciones del texto, lo que va de la mano con el uso de las teorías como "gran relato", que constatábamos anteriormente. Los autores son citados para apoyar alguna idea: "Sin embargo, tal como Foucault señala, el poder nunca es total, siempre hay resistencia

\footnotetext{
${ }^{15}$ En efecto, a pesar de iniciarse como etnólogo, en sus estudios sobre la sociedad Kabyl, en la década de 1960, Bourdieu viró posteriormente a intereses propiamente sociológicos. Él mismo se autodefinía como sociólogo. Las obras citadas en el corpus son en su mayoría pertenecientes a su período sociológico.
} 


\begin{tabular}{|l|c|l|l|}
\hline \multicolumn{2}{|c|}{ Forma que asume la teoría en la investigación } & \multicolumn{2}{c|}{ Forma de uso de la teoría en la investigación } \\
\hline Proposiciones vagas desconectadas del resto de la investigación & 50.5 & $\begin{array}{l}\text { Como “gran relato" desconectado del material } \\
\text { empírico }\end{array}$ & 39.2 \\
\hline $\begin{array}{l}\text { Proposiciones bien definidas con claro aporte al resto de la } \\
\text { investigación }\end{array}$ & 18.6 & $\begin{array}{l}\text { Como marco conceptual orientador del aná- } \\
\text { lisis }\end{array}$ & 30.9 \\
\hline Conceptos o proposiciones teóricas operacionalizadas & 4.1 & Marco hipotético operacionalizado & 4.1 \\
\hline Ausencia de teoría & 25.8 & Ausencia de teoría & 25.8 \\
\hline Total (\% y número de casos) & $\mathbf{1 0 0 ( n = 9 7 )}$ & Total (\% y número de casos) & $\mathbf{1 0 0 ( n = 9 7 )}$ \\
\hline
\end{tabular}

Tabla 3. Representación porcentual de usos de teoría y forma que asume la teoría. El cálculo excluye las investigaciones teóricas. Por eso " $n$ " equivale al total de investigaciones empíricas (97). En los casos en que los cálculos se hicieron para el total de investigaciones, se indica con una nota.

\begin{tabular}{|c|l|c|l|c|}
\hline Lugar & $\begin{array}{c}\text { Primer período } \\
1977-1987\end{array}$ & Citas & $\begin{array}{c}\text { Segundo período } \\
\text { 2000-2006 }\end{array}$ & Citas \\
\hline 1 & Lévi-Strauss & 37 & Bourdieu & 35 \\
\hline 2 & Malinowsky & 25 & Luhmann & 33 \\
\hline 3 & Foster & 25 & Foucault & 25 \\
\hline 4 & Godelier & 17 & Geertz & 19 \\
\hline 5 & Mead & 13 & Habermas & 16 \\
\hline 6 & Leach & 11 & Leach & 15 \\
\hline
\end{tabular}

Tabla 4. Frecuencias absolutas de los autores teóricos más citados en los dos períodos. Fuente: Período 1977-1988: reelaboración de datos obtenidos por Arnold (1990); Período 2000-2006: datos primarios de esta investigación.

a él y son aquellas resistencias las que lo hacen visible" (Benavente y Vergara 2006: 26), y los conceptos son utilizados de un modo puramente evocador: "Esta experiencia me recuerda lo que E. Goffman planteaba sobre la interacción social que puede caer a veces en una interrupción confusa y embarazosa, en la que la situación deja de estar definida..." (Recasens 2003:126).

Las teorías no son la única herramienta para construir el argumento de una investigación. Estas pueden apoyarse en referencias a otras investigaciones empíricas de la misma área temática, que actúan como antecedentes o marcos hipotéticos. Sólo $24.1 \%$ de las investigaciones hace una utilización significativa de otras investigaciones empíricas. Aquellas que no se apoyan en investigaciones empíricas tienden a coincidir con las que no utilizan teoría, lo que implica que se trata de investigaciones débilmente fundadas.

\section{Diseños metodológicos}

En esta sección analizamos los diseños metodológicos de las investigaciones. Las Tablas 5, 6 y 7 resumen las principales características metodológicas de las investigaciones antropológicas, según el grupo paradigmático al que adscriben. Los objetivos de conocimiento tienden a ser mayoritariamente comprensivos, de manera coherente con el predominio del paradigma interpretativo. El objetivo de explicar fenómenos, que supone una cierta concepción de causalidad, es muy minoritario, incluso en las investigaciones postpositivistas, en las cuales tiende a predominar la mera descripción de fenómenos.

Respecto a las técnicas de recolección, se observa el predominio de la entrevista individual abierta o entrevista en profundidad, la que es utilizada de manera exclusiva o en combinación con otras técnicas, en especial con la obser- 
vación participante, todas clásicas del método etnográfico. Algunos métodos están fuertemente asociados con su grupo paradigmático, por ejemplo, la encuesta para el postpositivismo, y el uso de documentos, frecuente en los dos grupos interpretativos. El porcentaje relativamente bajo de uso de datos secundarios indica la preferencia de los antropólogos por el trabajo de campo y la generación primaria de sus datos. Llama la atención el escaso uso de las entrevistas grupales (tanto focales como de discusión); se trata de técnicas que se han difundido de manera considerable en las ciencias sociales nacionales (Ramos 2005; Ramos et al. 2008). Las técnicas grupales asociadas a la intervención social (investigación acción, intervención sociológica), vinculadas a un paradigma crítico, no están representadas en la investigación antropológica.

Existe un marcado predominio de las técnicas cualitativas de análisis de los datos, lo que no sorprende, pues la investigación antropológica a nivel internacional se caracteriza por diseños cualitativos, a pesar que hay autores que afirman el creciente uso de técnicas cuantitativas multivariadas (Murmis 2005). Para el caso chileno esto no se constata a juzgar por el bajo uso de técnicas de asociación (solo una investigación utilizó análisis factorial) y el nulo uso de técnicas multivariadas de condicionamiento causal (regresiones múltiples, ANOVA, entre otras) o de reducción de datos (análisis de conglomerados, de correspondencias múltiples).

Lo que más llama la atención es la poca sofisticación de los procedimientos de análisis cualitativos. La gran mayoría de las investigaciones realiza análisis descriptivos de los datos obtenidos a través de las entrevistas u obser- vaciones; perspectivas interpretativas más desarrolladas como la hermenéutica, o el análisis de discurso son muy bajas, incluso en las investigaciones adscritas al primer grupo paradigmático.

Las técnicas de recolección, las de muestreo y los procedimientos de análisis son más bien rudimentarios, tanto en su variante interpretativa como postpositivista, lo que evidencia un bajo desarrollo metodológico. Lo anterior implica que no existe una estricta correspondencia entre los supuestos paradigmáticos y los diseños metodológicos. Así por ejemplo, las investigaciones postpositivistas emplean principalmente muestreos no probabilísticos y no hacen uso de procedimientos multivariados de análisis, como cabría esperar; las investigaciones interpretativas, por su parte, no utilizan la gama de métodos interpretativos disponibles. Además, hay una bajísima representación de diseños que incorporen a los sujetos en el proceso de investigación, y que usen la técnica de investigación acción.

\section{Audiencias y destinatarios}

El modo en que se diseña una investigación se relaciona estrechamente con quién va a ser su público. Es posible realizar una primera aproximación a las audiencias de las investigaciones antropológicas a través del análisis de los destinatarios explicitados o inferidos del texto y del uso proyectado del conocimiento generado (Burawoy 2004). A partir de ambos indicadores se ha clasificado a las investigaciones dependiendo de si van dirigidas a una audiencia interna, vale decir, al campo de las ciencias sociales, o a una audiencia externa.

\begin{tabular}{|l|c|c|c|c|}
\hline \multirow{2}{*}{ Objetivos de conocimiento } & \multicolumn{4}{|c|}{ Agrupamiento paradigmático } \\
\cline { 2 - 5 } & Interpretativo & Interpretativo crítico & Postpositivista & $\%$ \\
\hline Solamente descripción & 36.7 & 21.7 & 42.9 & 34 \\
\hline Interpretación/ comprensión & 61.7 & 73.8 & 42.8 & 61.9 \\
\hline Explicación/ predicción & 3.4 & 4.3 & 14.2 & 5.1 \\
\hline Evaluación & 0 & 4.3 & 14.2 & 3.1 \\
\hline Número de casos & 60 & $\mathbf{2 3}$ & $\mathbf{1 4}$ & 97 \\
\hline
\end{tabular}

Tabla 5. Representación porcentual de objetivos de conocimiento según agrupamiento paradigmático. Las categorías no son mutuamente excluyentes, de modo que las columnas no suman 100\%. Se excluyeron del cálculo las investigaciones teóricas. 


\begin{tabular}{|c|c|c|c|c|c|}
\hline & & \multicolumn{4}{|c|}{ Agrupamiento paradigmático } \\
\hline & & Interpretativo & Interpretativo crítico & Postpositivista & $\%$ \\
\hline \multirow{7}{*}{$\begin{array}{l}\text { Técnicas de } \\
\text { recolección }\end{array}$} & Entrevista individual no estandarizada (en profundidad) & 65 & 73.9 & 7.1 & 53.6 \\
\hline & Entrevistas individuales estandarizada (encuesta) & 5 & 4.3 & 57.1 & 12.4 \\
\hline & Entrevista grupal no estandarizada (grupo de discusión) & 6.7 & 4.3 & 7.1 & 6.2 \\
\hline & Entrevista grupal estandarizada (focus group) & 5 & 8.7 & 7.1 & 6.2 \\
\hline & Observación participante & 28.4 & 30.3 & $\circ$ & 24.7 \\
\hline & Uso de documentos & 40 & 52 & 7.1 & 38.1 \\
\hline & Datos secundarios & 5 & 21.5 & 49.9 & 15.3 \\
\hline \multirow{3}{*}{$\begin{array}{l}\text { Tipo de } \\
\text { muestreo }\end{array}$} & Probabilístico & 1.7 & 4.5 & 33.3 & $4 \cdot 4$ \\
\hline & No probabilístico & 93.2 & 100 & 55.6 & 90 \\
\hline & Censal & 5.1 & o & o & 2.2 \\
\hline \multicolumn{2}{|c|}{ Número de casos } & 60 & 23 & 14 & 97 \\
\hline
\end{tabular}

Tabla 6. Representación porcentual de las técnicas de recolección y tipos de muestreo según agrupamiento paradigmático:* Las categorías no son mutuamente excluyentes, de modo que las columnas no suman 100\%. Se excluyeron del cálculo las investigaciones teóricas.

\begin{tabular}{|c|c|c|c|c|c|}
\hline \multirow{2}{*}{\multicolumn{2}{|c|}{ Tipo de procedimiento de análisis interpretativo }} & \multicolumn{4}{|c|}{ Agrupamiento paradigmático } \\
\hline & & \multirow{2}{*}{$\frac{\text { Interpretativo }}{5}$} & \multirow{2}{*}{$\begin{array}{c}\text { Interpretativo crítico } \\
\circ\end{array}$} & \multirow{2}{*}{$\frac{\text { Postpositivista }}{50.0}$} & \multirow{2}{*}{$\frac{\%}{10.3}$} \\
\hline & Solo cuantitativo & & & & \\
\hline & Solo cualitativo & 90 & 82.6 & 7.1 & 76.3 \\
\hline \multirow{4}{*}{$\begin{array}{l}\text { Tipo de análisis } \\
\text { cuantitativo }\end{array}$} & Cuantitativo y cualitativo & 5 & 17.4 & 42.9 & 13.4 \\
\hline & Solo análisis descriptivo & 6.7 & 13 & 92.9 & 20.6 \\
\hline & Análisis de asociación & 34 & 8.6 & 50.0 & 11.4 \\
\hline & Condicionamiento causal & o & o & ○ & o \\
\hline \multirow{4}{*}{$\begin{array}{l}\text { Tipo de análisis } \\
\text { cualitativo }\end{array}$} & Análisis descriptivo etnográfico & 86.7 & $95 \cdot 5$ & 50.0 & 83.4 \\
\hline & Análisis estructural & 5.0 & ○ & ० & 3.1 \\
\hline & Análisis de discurso & 1.7 & 8.6 & ○ & 3.1 \\
\hline & Hermenéutica & ० & 4.3 & ○ & 1.0 \\
\hline \multirow{3}{*}{$\begin{array}{l}\text { Incorporación de los } \\
\text { sujetos a la } \\
\text { investigación }\end{array}$} & En el proceso de recolección de la información & 6.7 & o & o & $4 \cdot 1$ \\
\hline & En el proceso de análisis de la información & 1.7 & 8.7 & ० & 3.1 \\
\hline & No ocurre en ninguna de sus etapas & $93 \cdot 3$ & 91.3 & 100 & 93.8 \\
\hline \multicolumn{2}{|l|}{ Número de casos } & 60 & 23 & 14 & 97 \\
\hline
\end{tabular}

Tabla 7. Procedimientos de análisis según agrupamiento paradigmático. Las categorías no son mutuamente excluyentes, de modo que las columnas no suman $100 \%$. Se excluyeron del cálculo las investigaciones teóricas. 
Como se aprecia en la Tabla 8, hay tan solo un leve predominio de una audiencia académica por sobre la audiencia externa. Este es un dato interesante, pues a pesar de que en este estudio sólo se han considerado investigaciones descartándose otros tipos de texto, tales como los de divulgación o intervenciones en la prensa y foros públicos, la proporción de textos dirigidos a una audiencia no científica es muy alta. Como era de esperar, en el caso de la audiencia académica son preponderantes las investigaciones dirigidas a pares. Se trata de investigaciones en las que los propios antropólogos serían los más capacitados para comprender y evaluar el texto. En el caso de la audiencia externa hay $14.3 \%$ de investigaciones que corresponden a antropología aplicada, en la que los destinatarios son instituciones públicas o privadas que han demandado la investigación. Un $29.5 \%$ de investigaciones, no es investigación aplicada, no responde a una demanda particular, pero tampoco es investigación académica propiamente tal, a pesar de cumplir con los aspectos básicos de toda investigación. Son textos que abordan problemas sociales y manifiestan una postura, por lo general ética o normativa, ante asuntos colectivos.

\section{Distintas antropologías}

A través del análisis de correspondencias múltiples hemos querido posicionar las investigaciones respecto de algunas de las dimensiones que hemos comentado. Para generar el mapa de dos dimensiones se utilizaron las variables: grupo paradigmático, tipo de alteridad, tipo de audiencia y áreas temáticas.

Como se observa en la Figura 1, las investigaciones antropológicas chilenas muestran una alta dispersión, lo que indica la ausencia de unidad en términos paradigmáticos, epistemológicos y temáticos. No obstante, en esta dispersión se puede observar un ordenamiento con la forma de un triángulo invertido. En el vértice superior izquierdo del triángulo se posicionan las investigaciones caracterizadas por estudiar comunidades concebidas en términos de alteridad radical. Se trata de investigaciones abocadas al estudio de ritos y costumbres de comunidades étnicas desde una aproximación paradigmática interpretativa. Por las temáticas, así como por su construcción argumentativa, son los propios pares antropólogos quienes están mejor capacitados para evaluar y entender dichas investigaciones.
En el vértice inferior del triángulo, se ubican las investigaciones cuyo enfoque paradigmático es interpretativo crítico. En ellas se aprecia un mayor compromiso ético con la realidad estudiada. La relación con su objeto se plantea en términos de alteridad en contacto; se trata de investigaciones que tienden a centrarse en la relación entre instituciones nacionales y pueblos originarios, o que adoptan enfoques multiculturales o interculturales. Su modo de escritura, así como sus propósitos suelen ir más allá de la academia y del campo de la antropología, por lo que su audiencia tiende a ser la esfera pública interesada en dichos temas.

Finalmente, en el vértice superior derecho del triángulo se sitúan las investigaciones de antropología aplicada que, en su mayoría, se basan en una alteridad próxima, investigando fenómenos propios de la sociedad moderna como políticas públicas y problemas de desigualdad, con una importante presencia del paradigma pospositivista. Los temas de género, estudios urbanos y desarrollo local actúan como vínculo entre esta antropología aplicada y la segunda configuración, más crítica y caracterizada como alteridad en contacto.

\section{$*$ Conclusiones}

Nos propusimos examinar la producción de conocimiento de la antropología social chilena, manifestada en las investigaciones científicas recientes. Sus resultados deberán ser necesariamente complementados por un análisis del campo científico que tome en conside-

\begin{tabular}{|l|l|c|}
\hline Audiencia & \multicolumn{1}{|c|}{ Destinatarios } & $\%$ \\
\hline \multirow{2}{*}{ Académica } & $\begin{array}{l}\text { Pares, antropólogos con orientación } \\
\text { académica }\end{array}$ & 50 \\
\cline { 2 - 3 } & $\begin{array}{l}\text { Intelectuales, científicos en general } \\
\text { Externa }\end{array}$ & $\begin{array}{l}\text { Esfera pública, ciudadanía } \\
\text { Miembros de instituciones deman- } \\
\text { dantes, clientes }\end{array}$ \\
\hline \multirow{2}{*}{ Total } & & 29.5 \\
\hline
\end{tabular}

Tabla 8. Representación porcentual de audiencias y destinatarios para un total de 112 casos. 


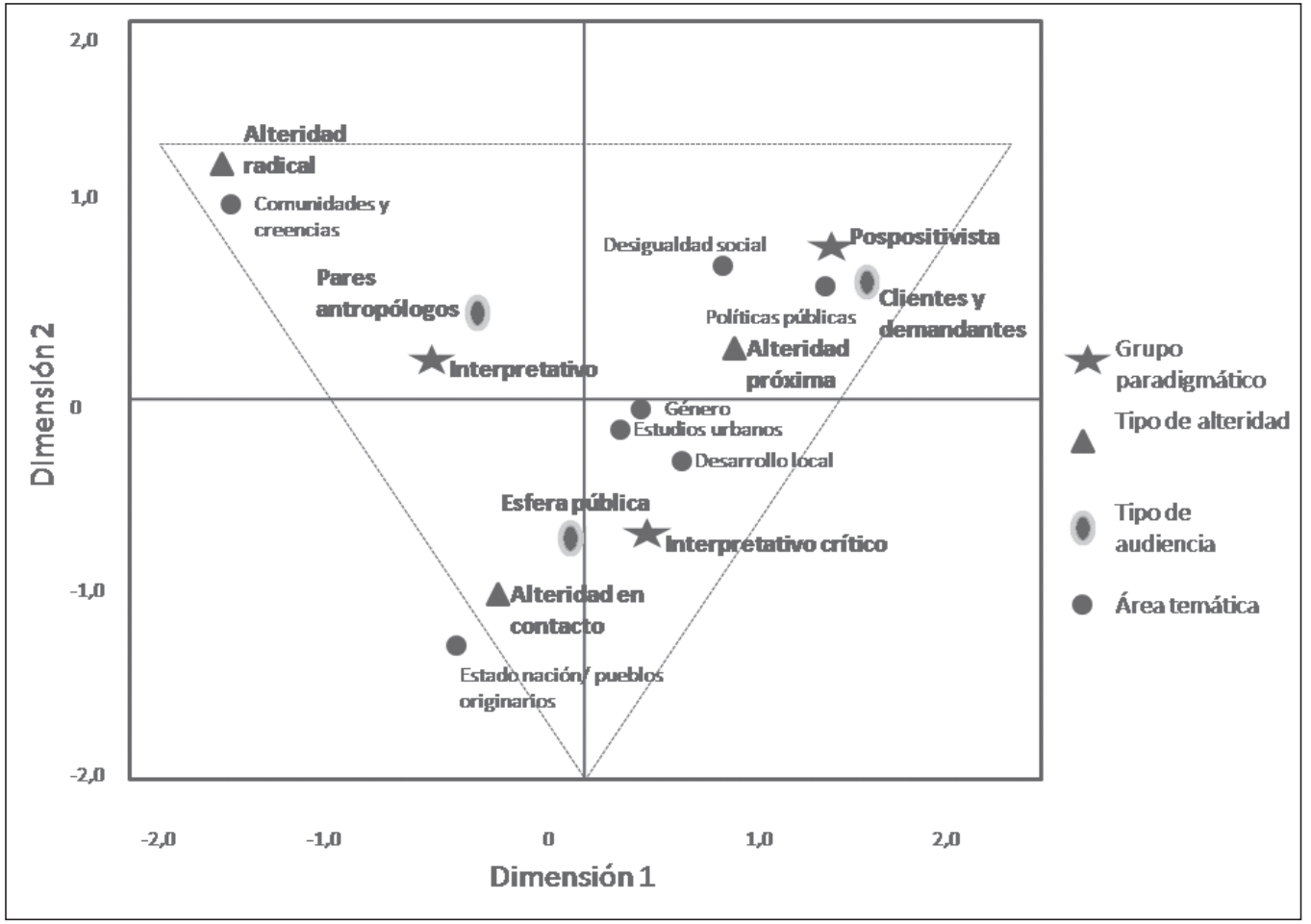

Figura 1. Análisis de correspondencias múltiples.

ración tanto los aspectos institucionales, como las redes de colaboración y competencia académica entre sus agentes. El análisis se ha hecho desde una perspectiva externa a la antropología, específicamente, desde la sociología de la ciencia y, aunque ha procurado considerar la trayectoria histórica de la disciplina, la lupa ha sido puesta en un período acotado de ésta. Desde esta óptica, el estudio ha puesto en evidencia que la producción científica reciente en la antropología social chilena se caracteriza por una alta dispersión epistemológica y temática, con significativas inconsistencias teóricas y metodológicas.

La mayoría de las investigaciones hace un uso precario de teorías, tanto generales como de rango medio. La operacionalización de conceptos teóricos o la construcción inductiva de teorías prácticamente es inexistente. Abunda, por el contrario, el uso de la teoría como "gran relato" que sirve como referencia a los argumentos de la investigación. Los autores y conceptos citados no son profundizados, sino que se los emplea en un sentido evocador o como respaldo a tesis propias. A pesar del uso instrumental y poco sustantivo de los argumentos y conceptos, algu- nos autores teóricos son profusamente citados. En general se trata de autores no directamente asociados al núcleo teórico-conceptual de la antropología, tales como Bourdieu, Luhmann, Foucault o Habermas, lo que mostraría una cierta "sociologización" de las preferencias teóricas.

El poco uso de las teorías para construir el argumento de las investigaciones, se asocia a un bajo empleo de referencias a otras investigaciones empíricas. Esto señala un riesgo para el desarrollo de la disciplina, pues implica que la mayoría de las investigaciones antropológicas (60\%) no se sustenta en teorías ni en otras investigaciones, tratándose de investigaciones "exploratorias" que abordan sus problemas de investigación desde cero, sin remitir al núcleo conceptual de su disciplina, ni al de las ciencias sociales en general.

Los diseños metodológicos de las investigaciones muestran también importantes debilidades. Se aprecia homogeneidad y poca sofisticación en las técnicas de recolección, de muestreo y de análisis de los datos. A pesar de la riqueza de sus objetos de estudio, las investigaciones antropológicas utilizan recurrentemente la entrevista abier$\underset{N^{3} 39 / 2010}{\text { ta }}$ el muestreo no probabilístico (por lo general errático)

ESTUDiOs ATACAMEÑOS

Arqueología y Antropología Surandinas 
y técnicas de análisis exclusivamente descriptivas. Esto sucede tanto en las investigaciones que adscriben a supuestos interpretativos, como en aquellas postpositivistas, lo que genera una gran inconsistencia paradigmática.

Una hipótesis posible es que las debilidades encontradas en las investigaciones antropológicas estén vinculadas a falencias institucionales, tanto en los programas de formación de los profesionales y científicos, como en los mecanismos de financiamiento y de regulación del campo. Esto amerita un análisis institucional y organizacional que no hemos desarrollado en esta ocasión. Sin embargo, la trayectoria histórica de la disciplina puede entregar algunas pistas. En efecto, la disciplina se institucionaliza en las universidades tardíamente, y en oposición, o al menos en discontinuidad, con los antropólogos y la posición paradigmática del período anterior. Esta brecha institucional, epistemológica e ideológica con la antropología desarrollada desde los museos, es sincrónica a las críticas internas que hace la disciplina a nivel mundial. El proceso de fundación de los primeros programas universitarios de antropología es interrumpido por el régimen militar y una parte de la generación de antropólogos chilenos que podría haber servido de puente entre ambos períodos, fue perseguida y debió exiliarse.

En ese sentido, el proceso de reestructuración institucional y epistemológica de la antropología chilena resultó truncado, y debió retomarse con dificultad a fines de la década de 1980, cuando la antropología mundial había efectuado grandes revisiones de sus fundamentos y de sus propósitos como ciencia social moderna. A nivel mundial en la antropología social se han venido produciendo algunas tendencias; por una parte, un desplazamiento desde una ciencia del "otro exótico" hacia una alteridad próxima, vale decir, una antropología centrada en el estudio de los fenómenos de la propia cultura de los investigadores. Esta tendencia, que emergería con fuerza luego de las críticas internas de la disciplina en los años 1960, responde a la toma de conciencia de la antropología europea, del colonialismo y de los procesos de mundialización que hacían epistemológicamente inviables y éticamente insostenibles los estudios de culturas remotas (Marcus y Fischer 2000). La otra tendencia, relacionada con la anterior, es la conformación de una antropología aplicada con una fuerte vocación pragmática y crítica, que se enfoca en temas como las políticas públicas o el desarrollo local, y que pretende alcanzar audiencias más allá de la academia (Peacock 1997; Okongwu y Mencher 2000; Rylco-Bauer et al. 2006).

Hemos discutido estas dos tendencias para la investigación antropológica reciente. La tendencia hacia una alteridad próxima no es evidente en la antropología nacional. En efecto, casi la mitad de las investigaciones analizadas se enfocan en el estudio de comunidades étnicas tanto desde una perspectiva distante (alteridad radical), como desde una perspectiva comprometida con el "otro" (alteridad en contacto). Tampoco se puede afirmar que la antropología chilena se caracterice por un predominio de la antropología aplicada. En efecto, en comparación con las temáticas investigadas entre 1977 y 1987 (Arnold 1990; Arnold y Haefner 1988), las investigaciones antropológicas actuales muestran un predominio de temas más tradicionales (estudios de comunidades, creencias y ritos) y enfocadas en la relación entre pueblos originarios y las instituciones del Estado nación.

En lugar de concordar con estas tendencias generales hacia una alteridad próxima y una antropología aplicada, en Chile se constata una antropología social más bien fragmentada, sin facciones consolidadas debido a un proceso de institucionalización complejo e interrumpido por condiciones políticas adversas, en tiempos de una radical transformación disciplinar a nivel mundial.

Agradecimientos Este artículo es resultado del Proyecto FONDECYT 1070814: "El estado de las ciencias sociales en el Chile postransición", cuyo objetivo es el análisis de la producción de conocimiento, de las redes comunicacionales y las bases institucionales de la antropología, de la ciencia política y de la sociología actualmente en Chile. Los autores agradecen los valiosos comentarios de los profesores Hans Gundermann y Mariza Peirano así como de los revisores anónimos. 


\section{* Referencias citadas}

ABEND, G., 2006. Styles of sociological thought: Sociologies, epistemologies, and the Mexican and U.S. quests for truth. Sociological Theory 24 (1): 1-32.

ARAVENA, A., 2005. Reconocimiento jurídico, políticas de desarrollo y etnicidad en Chile: El rol de las políticas públicas en el discurso étnico. Actas del $V$ Congreso de Antropología Chilena, pp. 741-750. Santiago.

ARNOLD, M., 1990. La antropología social en Chile. Producciones y representaciones. Universidad de Chile, Santiago.

2005. Desde dónde y hacia dónde: Antropología y desarrollo. Revista de Ciencias Sociales 1: 149-157.

ARNOLD, M. y C. HAEFNER, 1988. Análisis del contenido de las tesis de grado en la Licenciatura en Antropología de la Universidad de Chile en sus menciones de antropología social y cultural: 1977 a 1987. Serie Documentos de Estudio Antropología Social, Universidad de Chile, Santiago.

ARRIAGADA, P., 2006. Jóvenes y hip hop en Santiago. Nuevas imágenes y tensiones identitarias. Proposiciones 35:220-233.

ARROYO, B., 2005. Entrevista a Bernardo Berdichewsky. Austerra 2:15-27

BARTH, F, A. GINGRICH, R. PARKIN y S. SILVERMAN, 2005. One discipline, four ways: British, German, French, and American anthropology. University of Chicago Press, Chicago.

BENAVENTE, M. C. y C. VERGARA, 2006. Sexualidad en hombres y mujeres. Diversas miradas. FLACSO, Santiago.

BENGOA, J., 1998. Trayectoria de la antropología en Chile. Academia de Humanismo Cristiano, Santiago.

2000. La emergencia indígena en América Latina. Fondo de Cultura Económica, México D. F.

BERDICHEWSKY, B., 2004. Alejandro Lipschutz: Su visión indigenista y antropológica. Ediciones Universidad Católica Raúl Silva Henríquez, Santiago.

BURAWOY, M., 2004. Public sociologies: Contradictions, dilemmas and possibilities. Social Forces 82 (4): 1603-1618.

CANCINO, R., 2006. Capital social y estudios de la ciencia y la tecnología. Revista MAD 15: 1-11.
CARREÑO, G., 2002. Fotografías de cuerpos indígenas y la mirada erótica: Reflexiones preliminares sobre algunos casos del confín austral. Revista de Antropología Visual 2: 1-8.

2005. Pueblos indígenas y su representación en el género documental: Una mirada a los casos aymara y mapuche. RevistaAustral de Ciencias Sociales 9: 85-94.

CASTRO, M., 2005. Challenges in Chilean intercultural policies: Indigenous and economic development. Polar 28 (1): 112-132.

DURÁN, T., 2001. Antropología interactiva: Un estilo de antropología aplicada en la IX región de La Araucanía, Chile.Cultura, Hombre y Sociedad 6: 23-57.

DURÁN, T., N. CARRASCO y M. BERHÓ, 2005. Reflexividad y contexto en el quehacer antropológico. CUHSO 9 (1):38-50.

DURSTON, J., D. DUAHRT, F. MIRANDA y E. MONZÓ, 2005. Comunidades campesinas, agencias públicas y clientelismos políticos en Chile. LOM, Santiago.

GARRETÓN, M. A., 2005. Social sciences and society in Chile: Institutionalization, breakdown and rebirth. Social Science Information 44 (2-3): 359-409.

GAVILÁN, V., 2002. Buscando vida... Hacia una teoría aymara de la división del trabajo por género. Chungara 34 (1): 101-117.

GODOY, C., 2003. Sitios mapuche en internet: Reimaginando la identidad. Revista de Antropología Visual 3: 58-83.

GUBA, E. e Y. LINCOLN, 1998. Competing paradigms in qualitative research. En The Handbook of Qualitative Research, N. Denzin e Y. Lincoln (Eds.), pp. 195-220. Sage Publications, Thousand Oaks.

GUNDERMANN, H., 2003. Sociedades indígenas, municipio y etnicidad: La transformación de los espacios políticos locales andinos en Chile. Estudios Atacameños 25: 55-77.

GUNDERMANN, H., R. FOERSTER y J. VERGARA, 2003. Mapuches y aymaras. El debate en torno al reconocimiento y los derechos ciudadanos. RIL Editores, Santiago.

GUNDERMANN, H., J. I. VERGARA y R. FOERSTER, 2005. Contar a los indígenas en Chile. Autoadscripción étnica en la experiencia censal de 1992 y 2002. Estudios Atacameños 30: 91-115.

HERRERA, S., 2004. El aborto inducido. ¿Victimas y victimarios? Catalonia, Santiago. 
KOTTAK, C., 2002. Antropología cultural. McGraw Hill, Madrid.

KUHN, T., 1971. La estructura de las revoluciones cientificas. Fondo de Cultura Económica, México D. F.

MARCUS, G. y M. FISCHER, 2000. La antropología como crítica cultural. Un momento experimental en las ciencias humanas. Amorrortu Editores, Buenos Aires.

MÁRQUEZ, F., 2002. Cultura y movilidad en los 90: Santiago, Buenos Aires y Montevideo. Proposiciones 34: 1-12.

MATHIESEN, M. E., O. MORA, I. CHAMBLÁS y G. NAVARRO, 2004. Familia, permisividad y juicio moral en estudiantes de enseñanza media de la provincia de Concepción. Psykhe 13 (1):3-20.

MATUS, C., 2005. El cuerpo extasiado: Experiencia y percepción del cuerpo en usuarios de MDMA en el contexto de la cultura electrónica de la ciudad de Santiago de Chile. Actas del V Congreso de Antropología Chilena, pp. 1043-1053. Santiago.

MERINO, M., R. MILLAMÁN, D. QUILAQUEO y M. PILEUX, 2001. Perspectiva interpretativa del conflicto entre mapuche y no mapuche sobre la base del prejuicio y la discriminación étnica. Persona y Sociedad 28 (1): 111-128.

MERTON, R., 1957. Social theory and social structure. The Free Press, Illinois.

MOULIAN, R., 2002. Las trampas de la memoria. Información, significación y sentido en los procesos de comunicación ritual. El caso del nguillatun huilliche. Revista Austral de Ciencias Sociales 6: 47-68.

MURMIS, M., 2005. Sociology, political science and anthropology: Institutionalization, professionalization and internationalization in Argentina. Social Science Information 44 (2-3): 227-282.

OKONGWU, A.y J. MENCHER, 2000. The anthropology of public policy: Shifting terrains. Annual Review of Anthropology 29:107-124.

ORELLANA, M., 1988. Las reformas de la Universidad de Chile y la institucionalización de las ciencias antropológicas. Estudios Sociales 58:41-68.

1996. Historia de la arqueología en Chile. Bravo y Allende Editores, Santiago.

PARKIN, R. 2005. The french speaking countries. En One disciplines, four ways: British, german, french and american anthropology, F. Barth, A. Gingrich, R. Parkin y S. Silverman (Eds.), pp. 157-25. University of Chicago Press, Chicago.
PEACOCK, J., 1997. The future of anthropology. American Anthropologist 99 (1): 9-17.

PEIRANO, M., 1991. The anthropology of anthropology. The Brazilian case. Série Antropología, Brasilia.

1998. When anthropology is at home: The different contexts of a single discipline. Annual Review of Anthropology 27: 105-128.

2003. The sins and virtues of anthropology. A reaction to the problem of methodological nationalism. Serie Antropología, Brasilia.

PIZARRO, I. y J. M. VARAS, 2004. Evaluación del funcionamiento del Programa de Subsidios de Tierras en las regiones VIII, IX, X y XII: Respecto a sus criterios de focalización. Sociedad Hoy 8: 133-155.

POBLETE, R., 2002. Educación intercultural bilingüe en Cerro Navia. Reivindicación indígena. ARCIS, Santiago.

RAMOS, C., 2005. Cómo investigan los sociólogos chilenos en los albores del s. XXI. Persona y Sociedad 19 (3): 85-119.

2008. ¿Sistema, campo de lucha o red de traducciones y asociaciones? Tres modelos para investigar la ciencia social y un intento de integración. Persona y Sociedad 22 (2): 9-52.

RAMOS, C., A. CANALES y S. PALESTINI, 2008. El campo de las ciencias sociales en Chile: ¿Convergencia disciplinar en la construcción del objeto de estudio? Cinta de Moebio 33: 171-194.

RECASENS, A., 2003. Pueblos del mar. Relatos etnográficos. Allende y Bravo Editores, Santiago.

RODRÍGUEZ, J. C., P. MIRANDA y P. MEGE, 2002. Etnografía de la Siberia Caliente. Una nota metodológica sobre un estudio en María Elena, el último pueblo salitrero. Estudios Atacameños 22:1-29.

ROGERS, S., 2001. Anthropology in France. Annual Review of Anthropology 30: 481-504.

RYLCO-BAUER, B., M. SINGER y J. WILLIGEN, 2006. Reclaiming applied anthropology: Its past, present and future. American Anthropologist 108 (1): 178-190.

SADLER, M., 2004. Así nacieron a mi hija. En Nacer, educar, sanar. Miradas desde la antropología de género, M. Sadler, M. E. Acuña y A. Obach (Eds.), pp. 15-66. Catalonia, Santiago.

THOMAS, C. y D. SALAZAR, 2000. Huaris y llacuaces: Un modelo representacional andino de dominación. Diálogo Andino 19: 87-109.

VAN KESSEL, J., 200o. Individuo y religión en los Andes. IECTA, Iquique. 